\title{
PSA Level Less than Ten
}

National Cancer Institute

\section{Source}

National Cancer Institute. PSA Level Less than Ten. NCI Thesaurus. Code C137689.

A blood concentration of prostate specific antigen less than $10 \mathrm{ng} / \mathrm{mL}$. 